\title{
Information Behavior on Video on Demand Services: User Motives and Their Selection Criteria for Content
}

\author{
Jennifer Gutzeit ${ }^{1}$, Isabelle Dorsch ${ }^{1}(\mathbb{C})$ and Wolfgang G. Stock ${ }^{1,2, *(1)}$ \\ 1 Department of Information Science, Heinrich Heine University Düsseldorf, D-40225 Düsseldorf, Germany; \\ jennifer.gutzei@@hhu.de (J.G.); isabelle.dorsch@hhu.de (I.D.) \\ 2 Department of Operations and Information Systems, University of Graz, A-8010 Graz, Austria \\ * Correspondence: wolfgang.stock@hhu.de
}

check for updates

Citation: Gutzeit, J.; Dorsch, I.; Stock, W.G. Information Behavior on Video on Demand Services: User Motives and Their Selection Criteria for Content. Information 2021, 12, 173. https://doi.org/10.3390/info12040173

Received: 18 March 2021

Accepted: 13 April 2021

Published: 16 April 2021

Publisher's Note: MDPI stays neutral with regard to jurisdictional claims in published maps and institutional affiliations.

Copyright: (c) 2021 by the authors. Licensee MDPI, Basel, Switzerland. This article is an open access article distributed under the terms and conditions of the Creative Commons Attribution (CC BY) license (https:// creativecommons.org/licenses/by/ $4.0 /)$.

\begin{abstract}
Introduction. Are viewers of video-on-demand ( $\mathrm{VoD}$ ) services more intrinsically (i.e., preferentially self-determined) or extrinsically (i.e., externally determined) motivated when selecting movies and series? For extrinsic motivation, we distinguish between algorithmically generated suggestions from the services and personal recommendations from other users. Methods. We empirically investigated the information behavior on video streaming services of users from German-speaking countries with the help of an online survey $(\mathrm{N}=1258)$. Results. Active $\mathrm{VoD}$ users watch videos online mainly on a daily basis. They are externally determined in the selection of their videos both by algorithmically generated recommendations from the systems and-to a higher extent-from personal suggestions from acquaintances, friends, and relatives. However, there is a clear indication that intrinsic motivation plays a major role in the selection of videos. Discussion. Users of $\mathrm{VoD}$ services move in a cycle between machine-generated recommendations, suggestions, and exchange of opinions from and with other people, and self-determined information behavior.
\end{abstract}

Keywords: video on demand; VoD services; information behavior; motivation; recommender systems; personal recommendations; intrinsic motivation; extrinsic motivation

\section{Introduction}

Information behavior is currently a very important research area in information science [1-6]. Information behavior includes the production of information as well as the search for and use of information [7]. In recent years, video on demand (VoD) services have been widely used. What kind of information behavior do VoD services' users display? How do users search for content on VoD services? How do they use information from others to select content?

The market for both free and paid video streaming services has been experiencing great growth for some years [8]. What are the special features of video streaming in terms of user behavior? In principle, the variety of offerings by video streaming services pose a great challenge for their users. There is a very wide choice, finding suitable media content can be a challenging task for the respective viewer [9]. In the past, partners, friends, or relatives, as well as daily newspapers and magazines, recommended movies or TV shows, but nowadays, algorithmic recommendation systems have been added to many internet platforms [10] and also to $\mathrm{VoD}$ services [11,12]. We have found lots of studies on VoD, but only a few on information behavior concerning VoD, e.g., [13-17], and also a few about content selection on VoD platforms [18-21]. There are three prototypical scenarios for selecting videos by users:

(1) Recommender systems of video streaming services provide their users with algorithmbased recommendations for specific media content and thus help viewers find suitable videos from the increasing variety of offerings. 
(2) Another approach to find suitable videos for oneself is to interact with other users and follow the suggestions of others. Of course, users can also actively give recommendations to other viewers themselves.

(3) In contrast to this more externally determined behavior, there is self-determined information behavior in video streaming services, where users are solely intrinsically motivated to determine what they watch.

If viewers were to rely exclusively on algorithms, this could create something similar to a filter bubble [22] for them; if they relied exclusively on personal recommendations, the danger of an echo chamber lurks [23]. In addition, the situation of a lock-in must be considered [24]. Viewers are locked in to one provider in the paid sector-unless they sign multiple contracts in parallel. One cannot access content from Disney+ as a Netflix user or vice versa. Potential filter bubbles or echo chambers would therefore be provider-specific. Although fragmenting filter bubbles and echo chambers tend to have negative connotations, one should not close one's eyes to them, but-on the contrary-one should be conscious of the dangers lurking there. However, with a healthy portion of self-determined selection behavior on the part of users and the critical questioning of recommendations, it should be possible to minimize any negative aspects of algorithms or echo chambers $[25,26]$.

VoD services-free of cost, such as YouTube (premium service excluded), or paid, such as Netflix - have created an upheaval in the media industry $[27,28]$. In addition, the constant availability of media has led to modified consumption, which has also given rise to the behavior of binge watching, watching series and movies for hours via the internet [29]. This is, at least, associated with a tendency among younger viewers to turn away from conventional media such as television, which are squeezed into a rigid program schedule.

Why this article? Information scientists know very little about how viewers orient themselves and what motives guide them when it comes to selecting specific media content on VoD. The overall research question is: How do viewers behave when selecting videos? We investigate the selection behavior and selection motives of $\mathrm{VoD}$ viewers on Prime Video, maxdome, Netflix, and Sky; the offerings of TV media libraries; and the free-to-use service YouTube. We exclude live streaming services [30] (such as Twitch or YouNow) as a rather little-used alternative during the period of analysis. However, some questionees added Twitch in the free-text field.

When speaking about users' motivations, we followed the approach of Ryan and Deci [31-35]. They distinguish between three regulatory styles of motivation, namely intrinsic motivation, extrinsic motivation, and amotivation. Motivations are determined either by the acting persons themselves (self-determination) or by other circumstances (nonself-determination). Apart from intrinsic motivations (which are always caused by internal aspects, i.e., by the acting persons' selves), motivations are caused by a combination of internal and external aspects. Intrinsically motivated human behavior is performed out of the acting person's interests, for which the primary rewards are the confirmation of one's own competence, or simply enjoyment. Deci and Ryan distinguish four kinds of extrinsic motivations. Integration means the internalization of extrinsic causes; identification is the adoption of external regulations for a special purpose; and introjection entails the actor's taking in of external regulations and the reaction to contingent consequences of those regulations. The "classic case" of extrinsic motivation is external regulation; here, people behave to get rewards or to avoid negative consequences-independently of their own preferences or norms. Finally, amotivation leads to non-activity, i.e., to refrain from an action. In the case of this study, amotivation leads users not to search for content on VoD services.

\section{Materials and Methods}

We investigated the information behavior on video streaming services of viewers in German-speaking countries (Germany, Austria, and Switzerland, as well as Germanspeaking users in other countries). The central question is whether users are intrinsically (i.e., preferably self-determined) or extrinsically (i.e., externally determined) motivated 
when selecting movies and series. For sources of extrinsic motivation, we distinguish between algorithmically generated suggestions from the services and recommendations from and to other users. There are three dimensions in this context: (1) the user is described by means of demographic information and their selection behavior on VoD services; (2) the video streaming service, with the aspects of content offering and machine-generated recommendations; and (3) other users who interact with the initial user and make or receive recommendations actively or passively, as well as offline or online. The following five research questions emerge, the first two of which are intended to examine the situation with VoD services, and the last three of which address selection criteria in the selection of content.

Research question 1: How often do users watch videos online?

Research question 2: Which video streaming services are used?

Research question 3: Do users engage with algorithmically generated recommendations from video streaming services?

Research question 4: Do users give recommendations to other users or follow their recommendations?

Research question 5: How distinct is the user's self-determined selection behavior?

Online survey-based questionnaires provide a means of generating quantitative data. Furthermore, they ensure anonymity, and thus, a high degree of unbiasedness to bare personal information, preferences, and own knowledge. Therefore, we decided to work with an online survey. It was active from 19 February 2019 to 31 March 2019. As an ethical review board in our faculty did not exist at the time our study started, we had to determine the ethical harmlessness of the research project ourselves, and followed suggestions for ethical research by applying online surveys such as consent, risk, privacy, anonymity, confidentiality, and autonomy [36]. The procedure used was non-probability sampling, more precisely, convenience sampling in combination with volunteer sampling [37]. The survey was available in German and English (Supplementary Materials).

With the online survey, we collected data about users, video services, and other users. The survey was pretested and then distributed via UmfrageOnline. The first question of the survey, "How often do you watch videos (movies, series, web videos) online?", allows us to collect data about the users and perform an initial screening of participants on the use or non-use of video streaming services. In the second question, "Which video streaming services do you use?", we were able to filter out additional non-relevant participants by using the answer option "I do not use video streaming services." Questions 3 to 10 dealt with users' information reception behavior, i.e., how ("alone" or "together with others"), how often ("daily", "weekly", etc.), and where (e.g., "at home," "on the road") they watch videos, and the user behavior was described via experiences with recommendations or suggestions ("Have you recommendations/suggestions already received or shared?", "How did you get recommendations?"). Question 11 was dedicated to the intrinsically motivated search for videos without any suggestions or recommendations from others. The last three questions identify the demographic data of each survey participant. They included age (10-100 years), gender (male, female, and diverse), and place of residence. The values of some questions were ordinally scaled. For the questions about the periodicity of use, we applied a 7-point Likert scale [38] ranging from "never" to "occasionally" (as a neutral option in the middle) to "always" (or "daily") and calculated the median, interquartile range (IQR), and Mann-Whitney U-test [39] in each of the further steps, using two independent variables as significance tests, namely for both male versus female and young versus older participants. At the beginning, a hierarchical cluster analysis was performed on some questions. This revealed four clusters. Since the characteristics of some clusters were similar, they were combined and served as the basis for creating our two age groups (age group 1: 10- to 49-year-olds, and age group 2: 50- to 100-year-olds). All calculations were performed using SPSS. 


\section{Results}

The sample generated $\mathrm{N}=1258$ valid questionnaires from participants in Germanspeaking countries. Of these, 609 participants $(48.4 \%)$ were male, 644 participants $(51.2 \%)$ were female, and 5 participants $(0.4 \%)$ were diverse.

\subsection{How Often Do Users Watch Videos Online? (Research Question 1)}

Figure 1 shows that both the younger age group 1 and the older age group 2 watch videos online on a daily basis. While the first age group predominantly watches online videos daily or even several times a day, there was an increased distribution of the second age group across the entire range of scales. Among the young participants, the median was 7.0 (always; with an extremely small dispersion, IQR: 1.0); for the older survey participants, the median was already reached at 6.0 (several times a week), although the dispersion was very large, with an IQR of 3.0. The difference between old and young viewers was highly significant $(p<0.001)$. The difference between men and women was not highly marked, as both groups had a median of 7.0 with an IQR of 1 . However, due to different value distributions, the gender differences were significant $(p<0.05)$.

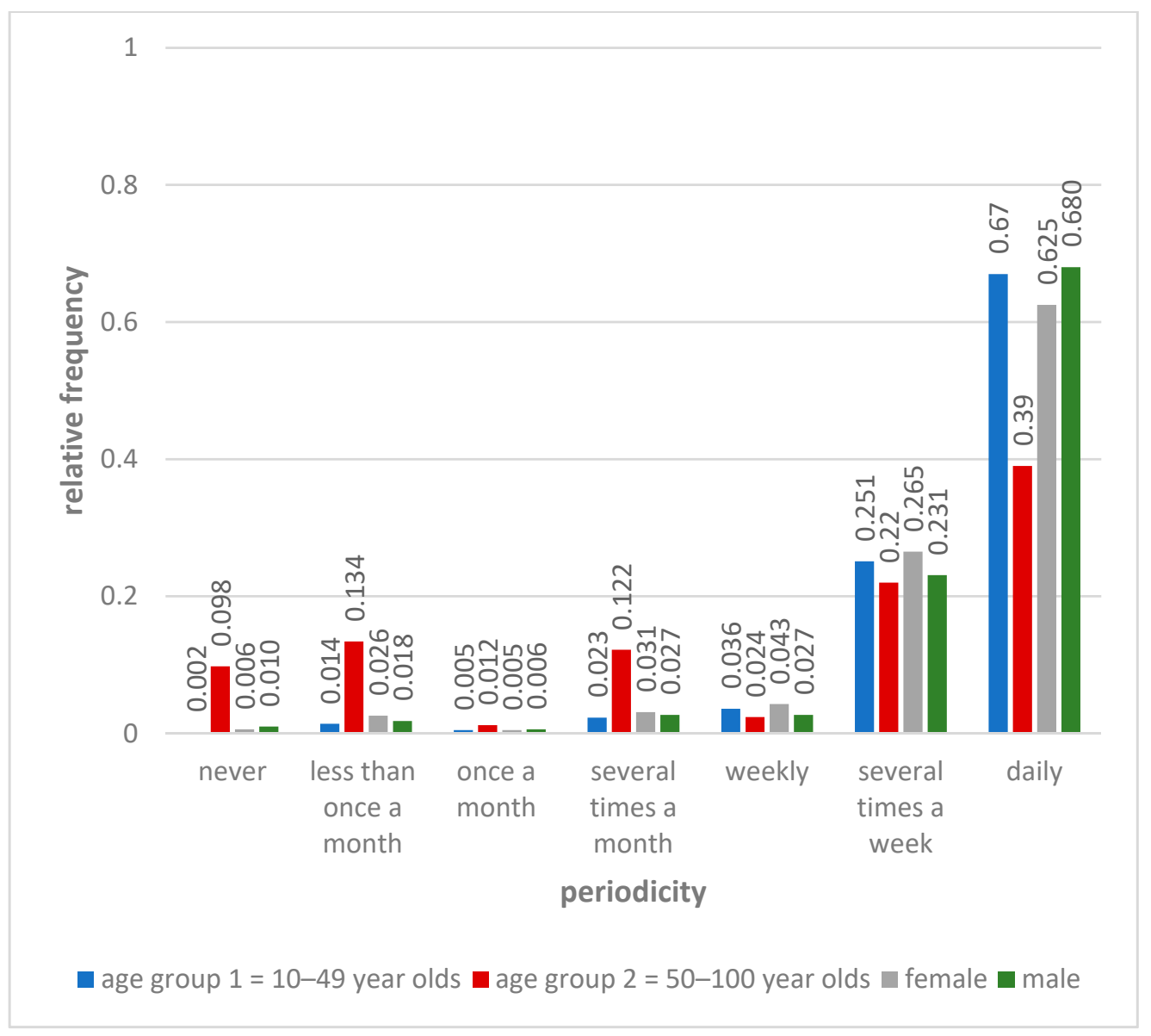

Figure 1. Viewing of $\mathrm{VoD}$ content by age $(\mathrm{N}=1258)$ and gender $(\mathrm{N}=1253)$ (relative frequencies). Question: How often do you watch videos (movies, TV shows, and videos on the Web) online?

\subsection{Which Video Streaming Services Are Used? (Research Question 2)}

The question "Which video streaming services do you use?" could be returned with multiple answers and optional additional answers in the free text fields. The given answers of video streaming services used were "Prime Video", "maxdome", "Netflix", "Sky", "TV media libraries", and "YouTube". 
In regard to all participants, "Netflix" (80.9\%) was used most frequently (Table 1), followed by "YouTube" and "Prime Video" with 75.8\% and 68.6\%, respectively. Of the specified services, "maxdome" (5.5\%) was used the least by the respondents. The social live streaming service "Twitch," which was not specifically listed in the survey, enjoys a non-negligible level of popularity. The other services from the additional responses, with values between $0.5 \%$ and $0.7 \%$, serve rather niche markets. When looking at the figures, it should be noted that the basic population are the active users of video services (and not the entire population). When comparing the age groups, it is noticeable that the younger group of the respondents uses a broader range of video streaming services. Thus, all services from the additional answers do not appear once among the older ones. Older respondents use Netflix $(70.0 \%)$ and Prime $(61.4 \%)$ less than the younger respondents (with relative frequencies of $81.6 \%$ and $69.0 \%$, respectively), but TV media libraries $(48.6 \%$; young: $34.3 \%$ ) more. There are hardly any differences between the genders for many services. However, female users are more likely to use Netflix (85.3\% vs. $76.4 \%$ ) and less likely to use YouTube (70.7\% vs. $81.4 \%)$. Twitch is used almost exclusively by men (3.9\%; in contrast to women: $0.3 \%)$.

Table 1. Frequencies of use of $\mathrm{VoD}$ services (multiple answers, additional answers from the free text field). Question: Which video streaming services do you use? $(\mathrm{N}=1258)$.

\begin{tabular}{ccc}
\hline VoD Service & Absolute Frequency & Relative Frequency \\
\hline Netflix & 1018 & $80.9 \%$ \\
YouTube & 954 & $75.8 \%$ \\
Prime Video & 863 & $68.6 \%$ \\
TV media libraries $^{\text {Sky }}$ & 441 & $35.1 \%$ \\
maxdome $^{\text {Twitch }}{ }^{1}$ & 277 & $22.0 \%$ \\
Other information $^{1}$ & 69 & $5.5 \%$ \\
DAZN $^{1}$ & 26 & $2.1 \%$ \\
TVNOW $^{1}$ & 25 & $2.0 \%$ \\
Vimeo $^{1}$ & 9 & $0.7 \%$ \\
\end{tabular}

${ }^{1}$ Additional answers.

\subsection{Do Users Engage with Algorithmically Generated Recommendations from Video Streaming} Services? (Research Question 3)

For the third research question, data was initially collected on how often and in what way respondents received recommendations from video streaming services. The results of the survey question "How often do you follow recommendations from video streaming services?" were then used to answer this research question. The choices were suggestions from the video streaming services which are offered on their platforms and personalized emails from the services that they send to their users. Suggestions from the video streaming services on their platforms were received rather frequently by the participants, although a clear trend was hardly recognizable. However, more recommendations were received through this channel than through personalized emails.

Respondents follow the recommendations they receive from video streaming services occasionally for the most part and frequently to a lesser extent (Figure 2). A comparison of the age groups shows that the older respondents tend to follow the recommendations slightly less frequently. The median for the younger respondents is 4.0 (with an IQR of 1.0) and the median for the older respondents is also 4.0 (with an IQR of 0 ), whereby the differences are highly significant $(p>0.001)$. The younger respondents follow the suggestions less occasionally than the older ones, but more frequently. Gender differences were not significant. The median of 4.0 (occasionally) for all users is a rather weak indicator of commitment to the algorithmically generated recommendations of the VoD services. 


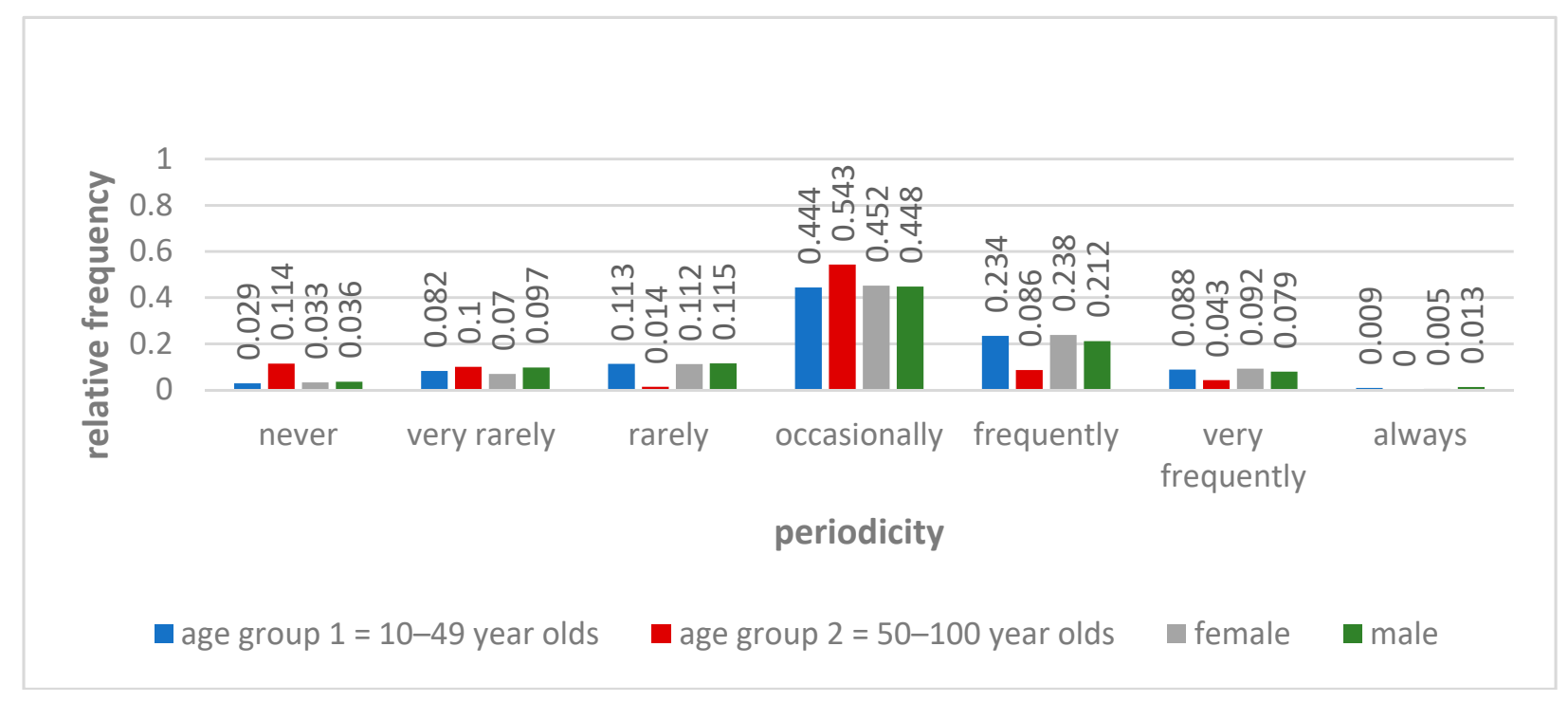

Figure 2. Following the VoD services' algorithmically generated recommendations by age $(\mathrm{N}=1258)$ and gender $(\mathrm{N}=1253)$ (relative frequencies). Question: How often do you follow recommendations from video streaming services?

\subsection{Do Users Give Recommendations to Other Users or Do They Follow Their Recommendations? (Research Question 4)}

To answer this research question, we evaluated the survey data from the questions: "How often have you recommended videos to acquaintances/friends/relatives?" (actively giving recommendations), "How often do you receive recommendations about videos from others?" (passively getting recommendations), and "How often do you follow others' recommendations?".

Table 2 shows that videos were actively recommended to friends, acquaintances, or relatives several times a month, and that recommendations were received from them just as frequently. The distributions of the data on giving and receiving recommendations are very similar. However, the results for following (passive) recommendations show different results: the values 1 to 3 (never, rarely, once a month) unite just $11.2 \%$ of all cases. $70.0 \%$ of the respondents follow the recommendations several times a month or weekly. $18.8 \%$ of the respondents even state that they follow the recommendations several times a week or daily. The median for followed recommendations is 5.0 (IQR is 1.0); for active recommendations, the median reaches only 4.0 (with a relatively large dispersion of 2.0). Respondents receive recommendations from other users most often through face-to-face conversations, occasionally receiving recommendations through personal messages (such as WhatsApp) or emails, and more rarely to never through social media advertising (for example, from influencers). There are some (few) significant differences between the generations. In terms of active recommendations, the younger respondents behave more actively (median: 4.0; IQR: 2.0) than the older respondents (median: 3.0; IQR: 2.0; $p<0.001$ ). The younger respondents were also more likely to follow the recommendations of others (median: 5.0; IQR: 1.0) than the older generation (median: 4.0; IQR: $1.0 ; p<0.001$ ). Particularly due to the frequent following of recommendations, especially among younger users, the effects of mutual influence between viewers cannot be excluded.

\subsection{How Distinct Is the User's Self-Determined Selection Behavior? (Research Question 5)}

Until now, the reader will know that users are externally determined in the selection of their videos both by recommendations from the services and - to a higher extent-from acquaintances, friends, and relatives, we conclude by asking how distinct intrinsic motivation is in the selection of content.

As shown in Figure 3, about $80 \%$ of the respondents search for videos occasionally to very frequently on their own initiative. The median is 5.0 (frequently) with an IQR of 2.0. 
Although the mean values are the same for the genders (at 5.0), men search for content more frequently (5), very frequently (6), or always (7) than women, who are more likely to search occasionally (4) on their own initiative. There is a clear indication (especially for male users) that intrinsic motivation plays a major role in the selection of videos.

Receiving personal recommendations: Question: How often do you receive recommendations about videos from others? $(\mathrm{N}=1258)$. Following personal recommendations: Question: How often do you follow others' recommendations? $(\mathrm{N}=1253)$. Giving personal recommendations: Question: How often have you recommended videos to acquaintances/friends/relatives? $(\mathrm{N}=1253)$.

Table 2. Giving and taking personal recommendations.

\begin{tabular}{cccc}
\hline & $\begin{array}{c}\text { Receiving Personal } \\
\text { Recommendations }\end{array}$ & $\begin{array}{c}\text { Following Personal } \\
\text { Recommendations }\end{array}$ & $\begin{array}{c}\text { Giving Personal } \\
\text { Recommendations }\end{array}$ \\
\hline Levs than once a month & $3.6 \%$ & $0.9 \%$ & $2.3 \%$ \\
(rarely) & $18.9 \%$ & $3.4 \%$ & $20.4 \%$ \\
Once a month & $15.5 \%$ & $6.9 \%$ & $17.2 \%$ \\
Several times a month & $30.8 \%$ & $34.8 \%$ & $30.3 \%$ \\
Weekly & $15.0 \%$ & $35.2 \%$ & $13.7 \%$ \\
Several times a week & $13.1 \%$ & $17.7 \%$ & $13.4 \%$ \\
Daily & $3.0 \%$ & $1.1 \%$ & $2.7 \%$ \\
Median & 4.0 & 5.0 & 4.0 \\
IQR & 2.0 & 1.0 & 2.0 \\
\hline
\end{tabular}

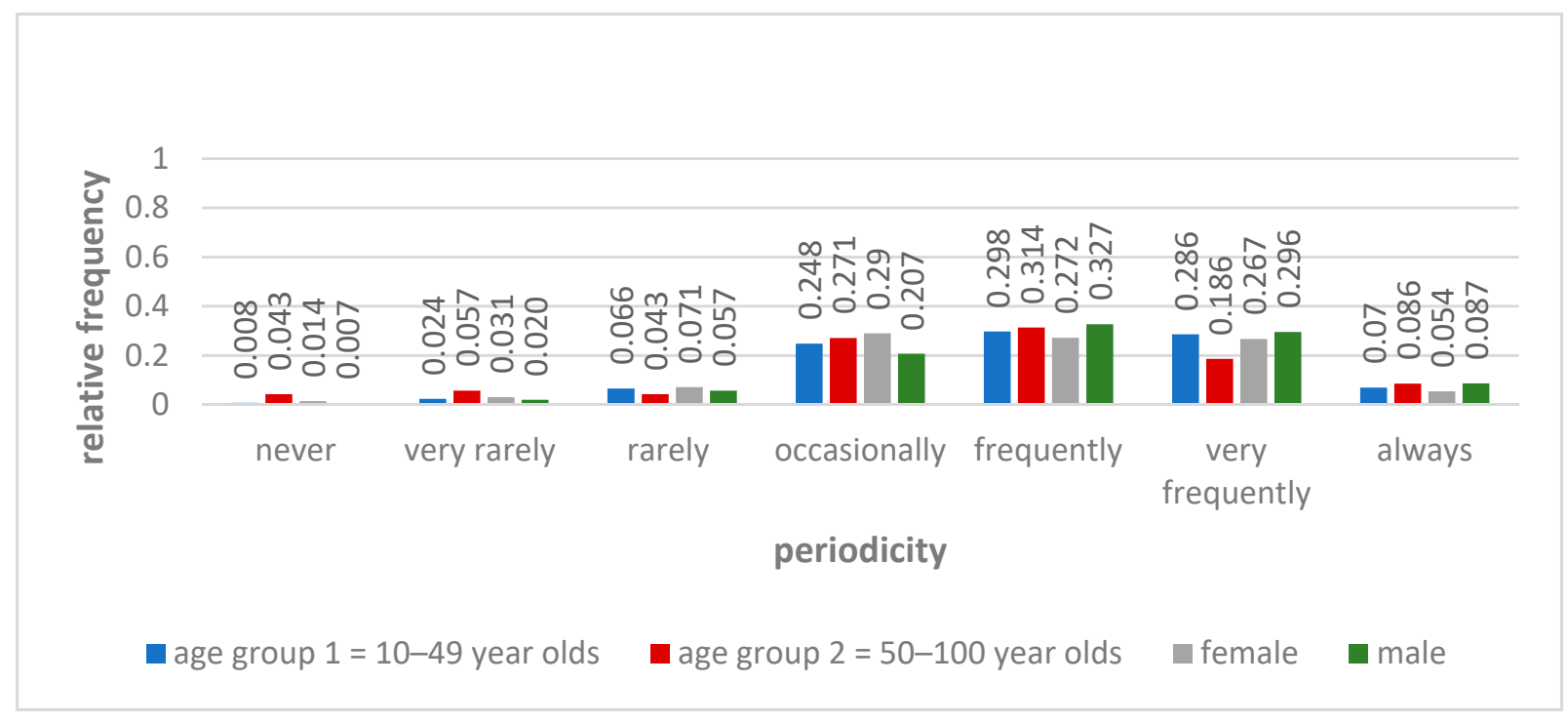

Figure 3. Active intrinsically motivated search behavior for new content on VoD services by age $(\mathrm{N}=1258)$ and gender $(\mathrm{N}=1253)$ (relative frequencies). Question: How often do you search for new videos?

\section{Discussion}

This research analyzes intrinsic (self-determined) and extrinsic information behavior of viewers on online video portals. The first research question dealt with the general use of VoD services. Here, a greater interest of the younger streaming customers was evident (the study did not examine non-users). This could be due to a higher affinity of younger people to the internet, as well as the fact that the content of the streaming platforms is more linked to the interests of the younger age group. There are no major differences between men and women. However, it can generally be said here that there is frequent video consumption (as a rule: daily). The second research question investigated which video streaming services are used most, and Netflix, YouTube, and Prime Video are used the most. 
The third research question deals with whether users follow the suggestions of the video streaming services. All participants receive recommendations through the suggestions or categories of the video streaming services, and also-although less frequently - through personalized emails from the services. There is little difference between male and female participants in the study, but greater differences among age groups. It is clear from the results that a large proportion of the users in the sample occasionally follow the recommendations of the video streaming services. However, the younger age group follows the recommendations of the video streaming services more often than the older age group. As a result, the research question can be answered that the users perceive the recommendations of the video streaming services, but do not follow them exclusively and not always. Following Pariser [22], systems' recommendations may lead to a phenomenon called a "filter bubble," which describes the users' uncritical following of those recommendations. Is there any danger of a filter bubble? As users by no means always follow the algorithmically generated recommendations, such danger is very low or even non-existent.

The fourth research question deals with interpersonal recommendations by examining interactions between the initial user and other users. Active and passive recommendations are each made or received several times a month on average, and they are frequently followed. Young and male participants are more likely to be influenced by other users than older and female participants. The interactions between users show that there is indeed an exchange of information that should not be underestimated, with the strong as well as weak ties of friends (and their friends, etc.) [40]. Is it possible that high amounts of active as well as passive recommendations lead the users into an echo chamber, i.e., a group of like-minded people favoring some content while ignoring all other [23]? In contrast to filter bubbles, echo chambers of VoD users cannot be ruled out.

From the results of research question five, it can be deduced that the usage behavior of the respondents is also intrinsic, and thus self-determined. From the self-determination theory it is evident that people, in this case users of video streaming services, act or do not act for certain motivational reasons. Since the interest in videos and new content appears to be high, users act out of intrinsic motivation and do indeed actively search for interesting content.

As a result of "old" habits in the consumption of TV programs and the predefined program selection of television stations, it has become normal for users to receive content in a certain variety of offerings. As recommendation systems on the internet preselect content for individual users or topic-specific groups by means of algorithms, online users have to mention a selection process that filters information and only outputs a portion of the possible offerings. Although the services' suggestions are generated by algorithms, they are based on past user behavior. Actions of the user (such as viewing habits), both extrinsically motivated by other users and from self-determined intrinsic motivation, thus influence the algorithms. These results are in line with Foster's for YouTube. He [21] (p. 123) concludes, "(a) that users are often prepared to follow suggestions from friends, who they may trust to recommend relevant content, and (b) users are probably indirectly influenced by anonymous other YouTube users through the algorithms that select videos for them to watch based on their search or previous watching history."

User behavior on VoD services is not influenced or even determined by just one factor, but by a combination of three aspects: (1) algorithmic recommendations, (2) suggestions from other viewers, and (3) self-determined active behavior. In a certain balance, all three determine user behavior. Extrinsic motivations resulting from algorithms occur least frequently (median: 4.0), and intrinsic self-determined and extrinsic motivations supplied by suggestions from others are about equally frequent (median: 5.0). Users of video streaming services move in a cycle between machine-generated suggestions, recommendations and exchange of opinions from and with other fellow human beings, and self-determined information behavior. This cycle does not necessarily flow in one direction, but can flow in several directions due to the factors mentioned, i.e., algorithms influence users, users influence algorithms, users influence each other and create groups of 
like-minded people, and self-determined information behavior has an effect on algorithms (which evaluate the behavior shown) and—insofar as content is actively recommended-on other viewers.

The study was limited to users in German-speaking countries. How does it look globally? Are there differences between our survey participants and others? The survey was carried out in 2019. It might be interesting to study if information behavior on VoD services might have changed since then due to new players (such as, for instance, Disney+) or new situations (such as the COVID-19 pandemic).

We decided to question active users by using an online survey and formulated questions such as "Do you follow recommendations?". Here, further studies should show whether such a methodical approach continues to prove its worth. By means of another survey, preferably combined with semi-structured interviews, motivations should be investigated in even greater detail. Which concrete intrinsic motivations guide users to self-determined information behavior? Additionally, which concrete extrinsic motivations occur preferentially in the algorithmic suggestions, as well as in the recommendations of other users? Are users even aware of the effects of external recommendations, i.e., the possibility of external determination by algorithms and other users? How often do users receive external recommendations, and how often do they follow them?

Supplementary Materials: The following are available online at https://www.mdpi.com/article/10 $.3390 /$ info12040173/s1. The questionnaire is attached as Supplementary Material.

Author Contributions: Conceptualization: all authors; methodology: all authors; empirical investigation: J.G.; data curation: J.G.; writing—original draft preparation: J.G.; writing: J.G. and W.G.S.; review and editing: all authors; visualization: J.G.; supervision: I.D. and W.G.S.; project administration: W.G.S. All authors have read and agreed to the published version of the manuscript.

Funding: This research received no external funding.

Informed Consent Statement: Informed consent was obtained from all subjects involved in the study.

Data Availability Statement: Data sharing not applicable.

Conflicts of Interest: The authors declare no conflict of interest.

\section{References}

1. Bates, M.J. Information behavior. In Encyclopedia of Library and Information Sciences, 3rd ed.; Bates, M.J., Maack, M.N., Eds.; CRC: New York, NY, USA, 2010; pp. 2381-2391.

2. Case, D.O.; Given, L.M. Looking for Information: A Survey of Research on Information Seeking, Needs and Behavior, 4th ed.; Emerald: Bingley, UK, 2016.

3. Fisher, K.E.; Erdelez, S.; McKechnie, L. Theories of Information Behavior; Information Today: Medford, NJ, USA, 2005.

4. Robson, A.; Robinson, L. Building on models of information behavior: Linking information seeking and communication. J. Doc. 2013, 69, 169-193. [CrossRef]

5. Savolainen, R. Information behavior and information practice: Reviewing the "umbrella concepts" of information-seeking studies. Libr. Q. 2007, 77, 109-132. [CrossRef]

6. Wilson, T.D. Human information behavior. Inf. Sci. 2000, 3, 49-55. [CrossRef]

7. Zimmer, F.; Scheibe, K.; Stock, W.G. A model for information behavior research on social live streaming services (SLSSs). Lect. Notes Comput. Sci. 2018, 10914, 429-448.

8. Birkel, M.; Kerkau, F.; Reichert, M.; Scholl, E. Markt und Nutzung kostenpflichtiger Streamingdienste. Pay-Video-on-Demand in Deutschland. Media Perspekt. 2020, 1, 22-32.

9. Baluja, S.; Seth, R.; Sivakumar, D.; Jing, Y.; Yagnik, J.; Kumar, S.; Ravichandran, D.; Aly, M. Video suggestion and discovery for YouTube: Taking random walks through the view graph. In Proceedings of the 17th International Conference on World Wide Web, New York, NY, USA, 1 April 2008; pp. 895-904.

10. Ricci, F.; Rokach, L.; Shapira, B.; Kantor, P.B. Recommender Systems Handbook; Springer: New York, NY, USA, 2011.

11. Gomez-Uribe, C.A.; Hunt, N. The Netflix recommender system: Algorithms, business value, and innovation. ACM Trans. Manag. Inf. Syst. 2015, 6. [CrossRef]

12. Hallinan, B.; Striphas, T. Recommended for you: The Netflix Prize and the production of algorithmic culture. New Media Soc. 2016, 18, 117-137. [CrossRef]

13. Yu, H.; Zheng, D.; Zhao, B.Y.; Zheng, W. Understanding user behavior in large-scale video-on-demand systems. In Proceedings of the 2006 EuroSys Conference, Leuven, Belgium, 18-21 April 2006; pp. 333-344. 
14. Sun, N.; Frey, D.; Jin, R.; Huang, H.; Chen, Z.; Rau, P.-L.P. A cross-cultural study of user experience of video on demand on mobile devices. Lect. Notes Comput. Sci. 2013, 8024, 468-474.

15. Miyazaki, M.; Fujisawa, H.; Nakagawa, T.; Okada, S.; Nitta, K. Relational analysis of users' viewing and communication behaviors in a video-on-demand service with social networking functions. Trans. Jpn. Soc. Artif. Intell. 2015, 30, 429-439. [CrossRef]

16. Yuan, Y.; Wang, X.; Bin, G. Analysis of user behavior in a large-scale internet video-on-demand (VoD) system. ACM Int. Conf. Proc. Ser. 2020, 153-158. [CrossRef]

17. Kofler, C.; Larson, M.; Hanjalic, A. User intent in multimedia search: A survey of the state of the art and future challenges. ACM Comp. Surv. 2016, 49, 1-37. [CrossRef]

18. Dogruel, L. Cross-cultural differences in movie selection. Decision-making of German, U.S., and Singaporean media users for video-on-demand movies. J. Int. Consum. Mark. 2018, 30, 115-127. [CrossRef]

19. Cunningham, S.J.; Nichols, D.M. How people find videos. In Proceedings of the 8th ACM/IEEE Joint Conference on Digital Libraries, JCDL '08, New York, NY, USA, 8 June 2008; pp. 201-210.

20. Albassam, S.A.A.; Ruthven, I. Users' relevance criteria for videos in leisure contexts. J. Doc. 2018, 74, 62-79. [CrossRef]

21. Foster, D. Factors Influencing the Popularity of YouTube Videos and Users' Decisions to Watch them. Ph.D. Thesis, School of Mathematics and Computing, University of Wolverhampton, Wolverhampton, UK, 2020.

22. Pariser, E. The Filter Bubble: What the Internet is Hiding from You; Viking: London, UK, 2011.

23. Dubois, E.; Blank, G. The echo chamber is overstated: The moderating effect of political interest and diverse media. Inf. Commun. Soc. 2018, 21, 729-745. [CrossRef]

24. Linde, F.; Stock, W.G. Information Markets. A Strategic Guideline for the I-Commerce; De Gruyter Saur: Berlin, Germany, 2011.

25. Zimmer, F.; Scheibe, K.; Stock, M.; Stock, W.G. Echo chambers and filter bubbles of fake news in social media. Man-made or produced by algorithms? In Hawaii University/International Conferences. 8th Annual Arts, Humanities, Social Sciences E Education Conference; Hawaii University: Honolulu, HI, USA, 2019; pp. 1-22.

26. Zimmer, F.; Scheibe, K.; Stock, M.; Stock, W.G. Fake news in social media: Bad algorithms or biased users? J. Inf. Sci. Theory Pract. 2019, 7, 40-53.

27. Rahe, V.; Buschow, C.; Schlütz, D. How users approach novel media products: Brand perception of Netflix and Amazon Prime video as signposts within the German subscription-based video-on-demand market. J. Media Bus. Stud. 2021, 18, 45-58. [CrossRef]

28. Lad, A.; Butala, S.; Bide, P. A comparative analysis of over-the-top platforms: Amazon Prime Video and Netflix. Lect. Notes Netw. Syst. 2020, 120, 283-299.

29. Matrix, S. The Netflix effect: Teens, binge watching, and on-demand digital media trends. Jeun. Young People Texts Cult. 2014, 6, 119-138. [CrossRef]

30. Scheibe, K.; Fietkiewicz, K.J.; Stock, W.G. Information behavior on social live streaming services. J. Inf. Sci. Theory Pract. 2016, 4, 6-20. [CrossRef]

31. Deci, E.L.; Ryan, R.M. Intrinsic Motivation and Self-Determination in Human Behavior; Plenum Press: New York, NY, USA, 1985.

32. Deci, E.L.; Ryan, R.M. Intrinsic and extrinsic motivations: Classic definitions and new directions. Contemp. Educ. Psychol. 2000, 25, 54-67.

33. Deci, E.L.; Ryan, R. Self-determination theory: A macrotheory of human motivation, development, and health. Can. Psychol. 2008, 49, 182-185. [CrossRef]

34. Deci, E.L.; Ryan, R.M. Self-Determination Theory: Basic Psychological Needs in Motivation, Development, and Wellness; Guilford: New York, NY, USA, 2017.

35. Vallerand, R.J. Toward a hierarchical model of intrinsic and extrinsic motivation. Adv. Exp. Soc. Psychol. 1997, 29, 271-360.

36. Buchanan, E.A.; Hvizdak, E.E. Online survey tools: Ethical and methodological concerns of human research ethics committees. J. Empir. Res. Hum. Res. Ethics 2009, 4, 37-48. [CrossRef] [PubMed]

37. Vehovar, V.; Toepoel, V.; Steinmetz, S. Non-probability sampling. In The SAGE Handbook of Survey Methodology; Sage: London, UK, 2016; pp. 327-343.

38. Likert, R. A technique for the measurement of attitudes. Arch. Psychol. 1932, 22, 5-55.

39. Mann, H.; Whitney, D. On a test of whether one of two random variables is stochastically larger than the other. Ann. Math. Stat. 1947, 18, 50-60. [CrossRef]

40. Granovetter, M.S. The strength of weak ties. Am. J. Sociol. 1973, 78, 1360-1380. [CrossRef] 